\title{
Manejo hídrico na rustificação em mudas de Maytenus ilicifolia [(Schrad.) Planch.]
}

\author{
João Alexandre Lopes Dranski ${ }^{1 *}$ \\ Ubirajara Contro Malavasi ${ }^{2}$ \\ Marlene de Matos Malavasi ${ }^{2}$ \\ ${ }^{1}$ Faculdade Educacional de Medianeira \\ Rua Rio Branco, 11820, CEP 85884-000, Medianeira - PR, Brasil \\ ${ }^{2}$ Universidade Estadual do Oeste do Paraná, Centro de Ciências Agrárias \\ Rua Pernambuco, 1777, CEP 85960-000, Marechal Cândido Rondon - PR, Brasil \\ * Autor para correspondência \\ joaodranski@yahoo.com.br
}

Submetido em 22/09/2016

Aceito para publicação em 03/01/2017

\section{Resumo}

Avaliou-se o efeito do tamanho da muda e do manejo da irrigação ao final do ciclo de produção sobre a qualidade de mudas de Maytenus ilicilofia. O experimento seguiu o delineamento inteiramente ao acaso em arranjo fatorial $2 \times 3$, em que mudas de duas classes de altura (maior ou menor que $18,0 \mathrm{~cm}$ ) foram submetidas a três regimes hídricos (rega diária, rega a cada dois dias e redução gradativa da irrigação). Após oito semanas, quantificaram-se atributos morfofisiológicos e de desempenho. A redução gradativa da irrigação promoveu maior taxa de assimilação líquida de carbono. A rega a cada dois dias possibilitou maior taxa de crescimento secundário, velocidade de acúmulo de biomassa nos tecidos aéreos e radiculares, com menor taxa de extravasamento de eletrólitos. Após o plantio, esses tratamentos mantiveram o maior teor relativo de água nas folhas (TRA). O TRA em mudas de menor tamanho foi significativamente maior até a terceira semana do plantio. Portanto, mudas de maior tamanho, submetidas à rustificação por redução gradativa do regime de regas, apresentam melhor qualidade.

Palavras-chave: Déficit hídrico; Espinheira-santa; Produção de mudas; Qualidade de mudas

\section{Abstract}

Water management in hardening Maytenus ilicifolia (Schrad.) Planch. seedlings. This study evaluated the effects of seedling height and irrigation management on M. ilicilofia seedlings. The experiment used a completely randomized design in a 2 x 3 factorial arrangement. Seedlings of two height classes (greater than or less than $18.0 \mathrm{~cm}$ ) were subjected to three irrigation regimes (daily irrigation, irrigation every other day, and gradual reduction of irrigation). After eight weeks, the morphophysiological and performance attributes of the seedlings were quantified. Gradual reduction of irrigation promoted the highest rate of net carbon assimilation. Irrigating every other day resulted in greater secondary growth rate, biomass accumulation in the shoot and root tissues, and lower electrolyte leakage rate. After planting, these treatments maintained higher leaf relative water content (RWC). RWC in seedlings smaller than $18 \mathrm{~cm}$ was significantly higher until the third week after planting. Therefore, larger seedlings submitted to hardening by gradually reducing irrigation improves seedling quality.

Key words: Drought stress; Espinheira-santa; Seedling production; Seedling quality 


\section{Introdução}

Mudas de espécies lenhosas são afetadas severamente por diversas formas de estresse biótico e abiótico, principalmente nas primeiras semanas pósplantio, considerado período crítico para o sucesso na implantação de povoamentos florestais. As respostas visuais do crescimento vegetal relacionadas aos diferentes mecanismos ou processos fisiológicos desencadeados durante aquele período são agrupadas na denominação de "choque pós-plantio", devido à necessidade da reconexão entre a raiz e o solo, possibilitando a sobrevivência de mudas produzidas em recipientes (RITCHIE et al., 2010; CLOSE, 2012).

A rustificação refere-se ao conjunto de práticas culturais adotadas durante a formação das mudas com finalidade de aumentar a tolerância ao choque do plantio. A adoção da prática cultural deve ainda refletir as condições ambientais e edáficas em que as mudas estarão propensas no campo (JACOBS; LANDIS, 2009).

A irrigação afeta aspectos morfofisiológicos relacionados à rusticidade de mudas. Alterações na condutância estomática, ajustamento osmótico, assimilação líquida de carbono e redução no crescimento da parte aérea com maior percentual de raízes são algumas evidências em estudos de condicionamento à deficiência hídrica (BAÑON et al., 2006; THOMAS, 2009; VILLAR-SALVADOR et al., 2013).

Na produção de mudas por sementes de espécies lenhosas da flora brasileira, a heterogeneidade do crescimento aéreo é corriqueiramente observada dada a variabilidade genética das matrizes assim como o manejo no viveiro, gerando mudas com diferentes padrões de qualidade e onerando a classificação antevendo a expedição (VOLKWEIS et al., 2014).

A altura da muda exerce influência direta na sobrevivência e no crescimento a campo. Figueiredo et al. (2011) reportaram que mudas clonais do híbrido de Eucalyptus grandis [Hill ex Maiden] x E. urophylla [S. T. Blake] de maiores altura e diâmetro apresentaram maior crescimento inicial no primeiro ano em sítios de diferentes condições edafoclimáticas. Del Campo et al. (2010) descreveram que a sobrevivência de mudas de Quercus ilex L. no campo foi correlacionada positivamente com o diâmetro do coleto e negativamente com a altura das mudas expedidas para o plantio.

Maytenus ilicifolia ocorre em toda a região ecológica da Floresta Estacional Semidecidual, possuindo potencial para programas de reflorestamento com fins conservacionistas e para extração de compostos químicos das folhas. Isso faz com que a espécie seja cultivada para fins econômicos (DUARTE; DEBUR, 2005; BOEGER et al., 2009).

Na região oeste do Paraná, os principais entraves para o sucesso do estabelecimento de povoamentos florestais é a precipitação irregular, ocorrendo períodos de estiagem durante a janela de plantio (NERY et al., 2002). Portanto, a produção de mudas condicionadas a períodos de deficiência hídrica pode elevar o sucesso do plantio.

O ensaio avaliou os efeitos do tamanho da muda e da restrição hídrica ao final do ciclo de produção sobre a qualidade de mudas de M. ilicilofia.

\section{Material e Métodos}

O experimento foi instalado em ambiente protegido localizado em Marechal Cândido Rondon, PR durante os meses de agosto de 2010 a julho de 2011. A temperatura média do ambiente propagativo manteve-se a $27,0 \pm$ $3,0^{\circ} \mathrm{C}$ com umidade relativa do ar de $73,0 \pm 7,0 \%$.

$\mathrm{O}$ ensaio foi conduzido em delineamento inteiramente ao acaso em arranjo fatorial $(2 \times 3)$ composto por mudas classificadas de acordo com a altura (maiores ou menores do que $18,0 \mathrm{~cm}$ ) e por três regimes hídricos na fase de rustificação.

Os regimes hídricos foram: diário (controle); rega a cada dois dias (intercalar); e gradativo, que consistiu na redução gradativa da irrigação por oito semanas (primeira e segunda semanas com regas diárias, terceira e quarta semanas com regas a cada dois dias, quinta e sexta semanas com regas a cada três dias, e sétima e oitava semana com regas a cada quatro dias) com quatro repetições de dezesseis mudas. As mudas foram irrigadas, por aspersão, até a saturação.

A semeadura ocorreu em agosto de 2010 em tubetes 
de seção circular e volume de $120 \mathrm{~cm}^{3}$, preenchidos com uma mistura de substrato comercial a base de casca de Pinus e solo local na proporção de 4:1 (v.v.), acomodados em bandejas de plásticas com capacidade para 96 recipientes.

A fertilização constou de $50 \mathrm{~g}$ de fertilizante de liberação controlada (Osmocote ${ }^{\circledR}$ Mini Prill 5-6 meses) da formulação $\mathrm{N}_{2}-\mathrm{P}_{2} \mathrm{O}_{5}-\mathrm{K}_{2} \mathrm{O}(18-5-9)$ para $25 \mathrm{~kg}$ de substrato.

O tempo de formação das mudas foi de 52 semanas após a semeadura. Quando as plântulas apresentavam $10 \mathrm{~cm}$ de altura realizou-se a redução pela metade da ocupação dos tubetes nas bandejas de plástico. As mudas foram irrigadas diariamente às $9 \mathrm{~h}$ por aspersão até a capacidade de campo.

O tempo de crescimento foi de 26 semanas após a emergência, quando então foram tomadas as medidas da altura de todos os indivíduos e agrupadas com base na distribuição de frequências em duas classes (Tabela 1). Após a categorização, mensurou-se o diâmetro do coleto, a área foliar e a massa seca dos tecidos aéreos e radiculares em amostras de oito mudas escolhidas aleatoriamente por tratamento. Neste momento, iniciou-se o manejo da irrigação que perdurou por oito semanas.

Ao final da imposição dos tratamentos, todas as mudas foram reidratadas e após $24 \mathrm{~h}$ avaliaram-se, em quatro mudas por repetição, as taxas de assimilação líquida de carbono $(A)$, condutância estomática $\left(g_{s}\right)$, transpiração $(E)$, temperatura foliar (Tf) e a concentração de $\mathrm{CO}_{2}$ intracelular (Ci). As taxas de $A, g_{s}, E$, Tf e $\mathrm{Ci}$ foram medidas em sistema aberto, sob luz saturante artificial $\left(1.200 \mathrm{mmol} \mathrm{m}^{-2} \mathrm{~s}^{-1}\right)$ e concentração de $\mathrm{CO}_{2}$ ambiente sob temperatura constante de $25^{\circ} \mathrm{C}$, com o auxílio de um analisador de gás infravermelho portátil
(LI-6400XT). As avaliações foram efetuadas pela manhã, das $9 \mathrm{~h}$ às $11 \mathrm{~h}$, seguindo a orientação cardeal, na última folha recém-expandida.

Após a aferição das trocas gasosas, foi mensurada a área foliar, foram calculados os incrementos na altura (IH), no diâmetro do coleto (ID) e foi determinada a relação entre altura e diâmetro do coleto $(\mathrm{H} / \mathrm{D})$. Os incrementos na massa seca de raiz (MSR) e na massa seca dos tecidos aéreos (MSA) foram quantificados através do método de secagem em estufa por $72 \mathrm{~h}$ a $65^{\circ} \mathrm{C}$ e os resultados expressos em mg por dia. Os resultados da biomassa foram então utilizados para estimativas da taxa de crescimento absoluto (TCA) em mg em quatro mudas por repetição.

A área foliar foi determinada pelo método de imagens digitalizadas com o software Quant (VALE et al., 2008). O número de folhas representativas para obtenção da área foliar média foi determinado pelo método de amostragem aleatória simples, com base na variância da média de 20 folhas por tratamento, coletadas de diferentes posições na muda. Admitiu-se o limite de erro de $15 \%$ a $95 \%$ de probabilidade pelo teste $\mathrm{t}$ de Student para uma população que tende ao infinito, como sugerido por Pellico Netto e Brena (1997). Após a determinação da área foliar média, multiplicou-se pelo número de folhas para obtenção da área foliar por muda e os resultados foram expressos em $\mathrm{dm}^{2}$ por muda.

Complementarmente, utilizou-se o teste do extravasamento de eletrólitos das raízes (PER) proposto por Wilner (1955) em raízes obtidas de quatro mudas por repetição. Para a quantificação do PER, as raízes de cada muda foram lavadas em água corrente para remoção de partículas do solo, a que se seguiu de lavagem com água deionizada. A porção central do sistema radicular foi removida e descartada. Utilizou-se aproximadamente

TABELA 1: Valores médios da altura (H), diâmetro do coleto (D), área foliar (AF), massa seca de raízes (MSR) e dos tecidos aéreos (MSA) em função do tamanho das mudas de Maytenus ilicifolia.

\begin{tabular}{lccccc}
\hline \multirow{2}{*}{ Tamanho da muda } & $\mathbf{H}$ & $\mathbf{D}$ & $\mathbf{A F}$ & MSR & MSA \\
\cline { 2 - 6 } & $\mathbf{c m}$ & $\mathbf{m m}$ & $\mathbf{d m}^{2}$ & ------ g por muda ----- \\
\hline$>18,0 \mathrm{~cm}$ & $21,8 \pm 1,6^{*}$ & $3,21 \pm 0,7$ & $3,39 \pm 0,20$ & $0,65 \pm 0,08$ & $1,96 \pm 0,12$ \\
$<18,0 \mathrm{~cm}$ & $15,7 \pm 1,4$ & $2,99 \pm 0,6$ & $1,87 \pm 0,29$ & $0,50 \pm 0,05$ & $1,47 \pm 0,17$ \\
\hline
\end{tabular}

* Desvio padrão da média. 
$0,2 \mathrm{~g}$ de raízes finas $(<2 \mathrm{~mm})$ retiradas do terço superior e acondicionadas em recipientes de vidro contendo 20 $\mathrm{mL}$ de água deionizada, mantidos a temperatura de $20^{\circ} \mathrm{C}$ por $24 \mathrm{~h}$. Após esse período, a condutividade elétrica da solução (CEv) foi obtida com condutivímetro termocompensado. Em seguida, as mesmas raízes foram autoclavadas a $100^{\circ} \mathrm{C}$ por $10 \mathrm{~min}$ e recolocadas em solução renovada nas mesmas condições anteriormente descritas. A condutividade elétrica da solução (CEm) foi quantificada da mesma maneira da CEv. O valor de PER foi calculado de acordo com a Equação 1.

$$
\operatorname{PER}(\%)=\frac{\mathrm{CEv}}{\mathrm{CEm}} \times 100
$$

Após o término da rustificação, seis mudas por repetição foram transplantadas para vasos de $22 \mathrm{dm}^{3}$ preenchidos com solo da região (Latossolo Vermelho Distroférrico típico, de textura argilosa) e permaneceram por nove semanas em ambiente protegido. Os vasos foram irrigados até a capacidade de campo no ato do plantio e em seguida houve a suspensão total da irrigação. Nessa fase adotou-se o delineamento em blocos ao acaso em arranjo fatorial ( $2 \times 3 \times 3)$, sendo o terceiro fator composto por avaliações a cada três semanas.

O teor relativo de água nas folhas (TRA) foi obtido de cinco discos foliares de $1,0 \mathrm{~cm}$ de diâmetro do limbo foliar (excluindo as nervuras) em diferentes folhas por muda, coletadas sempre às $14 \mathrm{~h}$. Após a coleta, obtevese a massa fresca (MF). Em seguida, os discos foram acondicionados em caixas de plástico do tipo gerbox com uma folha de papel filtro contendo $10 \mathrm{~mL}$ de água deionizada. As caixas foram acomodadas em câmara do tipo BOD durante $24 \mathrm{~h}$ a $10^{\circ} \mathrm{C}$. Após esse período, os discos foram novamente pesados para obtenção da massa túrgida (MT). Finalmente, os discos foram levados à estufa de circulação forçada de ar a $65^{\circ} \mathrm{C}$ por $72 \mathrm{~h}$, obtendo-se assim a massa seca (MS). O valor de TRA foi calculado de acordo com a Equação 2.

$$
\operatorname{TRA}(\%)=\frac{\text { MF-MS }}{\text { MT-MS }} \times 100
$$

Os dados foram averiguados quanto à normalidade da distribuição dos resíduos pelo teste de Lilliefors e quanto à homogeneidade da variância pelo teste de Cochran e Bartlet. Posteriormente, os dados foram submetidos à análise de variância com o auxílio do software SAEG ver. 9.1. Quando da existência de diferenças estatisticamente significativas, as médias foram comparadas pelo teste de Tukey a 5\% de probabilidade de erro.

\section{Resultados}

Todas as características avaliadas apresentaram distribuição normal dos resíduos e homogeneidade das variâncias a 5\% de probabilidade de erro. A análise de variância revelou não haver efeito de interação entre os fatores avaliados para as trocas gasosas bem como efeito isolado do tamanho da muda. Todas as características avaliadas apresentaram diferenças significativas para a fonte de variação regime hídrico.

O regime gradativo resultou no maior valor de $A$, mas manteve taxas de $g_{s}$ e $E$ semelhantes ao tratamento controle, porém com menor valor para $\mathrm{Ci}$, indicando maior eficiência de carboxilação de $\mathrm{CO}_{2}$ (Tabela 2). Já com o regime intercalar de irrigação ocorreu uma redução de $g_{s}$ e consequentemente em $E$ e $A$, minimizando a capacidade de assimilação de $\mathrm{CO}_{2} \mathrm{e}$ resultando no maior consumo do $\mathrm{CO}_{2}$ do mesófilo foliar. $\mathrm{O}$ tratamento controle, por manter maiores médias para $g_{s}$ e $E$, resultou na menor temperatura foliar.

Não foram detectados efeitos significativos dos regimes hídricos e da interação deste com o tamanho da muda $(p>0,05)$ na avaliação da área foliar. Porém, para o tamanho da muda foram detectadas diferenças significativas, sendo que mudas maiores que $18 \mathrm{~cm}$ apresentaram área foliar média de $4,65 \mathrm{dm}^{2}$ e nas menores que $18 \mathrm{~cm}$ a área foliar média foi $2,67 \mathrm{dm}^{2}$. O incremento em altura das mudas não foi influenciado pelo tamanho da muda (Tabela 3).

Em mudas menores que $18 \mathrm{~cm}$ de altura, o manejo hídrico intercalar reduziu em $40 \%$ o incremento na altura em comparação ao tratamento controle, enquanto o manejo hídrico gradativo não diferiu estatisticamente 
TABELA 2: Trocas gasosas em função do regime hídrico na fase de rustificação em mudas de Maytenus ilicifolia.

\begin{tabular}{|c|c|c|c|c|c|}
\hline \multirow{2}{*}{ Regime hídrico } & $A$ & $\mathbf{C i}$ & $g_{s}$ & $E$ & \multirow{2}{*}{$\frac{\mathbf{T f}}{{ }^{\circ} \mathrm{C}}$} \\
\hline & \multicolumn{2}{|c|}{$\mu \mathrm{mol} \mathbf{m}^{-2} \mathbf{s}^{-1}$} & \multicolumn{2}{|c|}{$\mu \mathrm{mol} \mathrm{m}^{-2} \mathrm{~s}^{-1}$} & \\
\hline Controle & $3,99 b^{*}$ & $234,5 \mathrm{a}$ & $51,2 \mathrm{a}$ & $810,7 \mathrm{a}$ & $23,5 b$ \\
\hline Intercalar & $3,36 \mathrm{c}$ & $172,8 \mathrm{c}$ & $29,1 b$ & $510,3 b$ & $24,7 \mathrm{a}$ \\
\hline Gradativo & $4,54 \mathrm{a}$ & $198,9 b$ & $48,7 \mathrm{a}$ & $750,9 a$ & $24,9 \mathrm{a}$ \\
\hline CV (\%) & 24,1 & 19,1 & 25,8 & 30,1 & 1,8 \\
\hline
\end{tabular}

* Médias seguidas da mesma letra na coluna não diferem estatisticamente entre si pelo teste Tukey a 5\% de probabilidade de erro. Em que: $(A)$ assimilação líquida de carbono; $(\mathrm{Ci})$ concentração de $\mathrm{CO}_{2}$ intracelular; $\left(g_{s}\right)$ condutância estomática; $(E)$ transpiração; (Tf) temperatura foliar.

TABELA 3: Incrementos na altura (IH), no diâmetro do coleto (ID) e relação entre altura e diâmetro do coleto (H/D) em função do tamanho e dos regimes hídricos em mudas de Maytenus ilicifolia na fase de rustificação.

\begin{tabular}{|c|c|c|c|c|c|c|}
\hline \multirow{3}{*}{ Regime hídrico } & \multicolumn{2}{|c|}{ IH } & \multicolumn{2}{|c|}{ ID } & \multicolumn{2}{|c|}{ H/D } \\
\hline & G & $\mathbf{P}$ & G & $\mathbf{P}$ & G & $\mathbf{P}$ \\
\hline & \multicolumn{2}{|c|}{----- cm ------ } & \multicolumn{2}{|c|}{----- mm ----- } & \multicolumn{2}{|c|}{--- $\mathbf{c m ~ m m}^{-1}$--- } \\
\hline Controle & $3,6 \mathrm{aA}^{*}$ & $4,5 \mathrm{aA}$ & $1,68 \mathrm{bA}$ & $0,96 \mathrm{cB}$ & $5,2 \mathrm{aA}$ & $5,1 \mathrm{aA}$ \\
\hline Intercalar & $3,3 \mathrm{aA}$ & $2,7 \mathrm{bA}$ & 1,86 abA & $1,98 \mathrm{bA}$ & $4,8 \mathrm{bA}$ & $3,6 \mathrm{bB}$ \\
\hline Gradativo & $4,5 \mathrm{aA}$ & 4,2 abA & $2,16 \mathrm{aA}$ & $2,28 \mathrm{aA}$ & $4,7 \mathrm{bA}$ & $3,6 \mathrm{bB}$ \\
\hline CV (\%) & \multicolumn{2}{|c|}{10,9} & \multicolumn{2}{|c|}{9,2} & \multicolumn{2}{|c|}{3,1} \\
\hline
\end{tabular}

* Médias seguidas da mesma letra minúscula nas colunas e maiúsculas nas linhas não diferem estatisticamente entre si ao nível de 5\% de probabilidade de erro pelo teste de Tukey. Em que: G: mudas com altura maior que $18 \mathrm{~cm}$; P: mudas com altura menor que $18 \mathrm{~cm}$.

dos demais tratamentos. Em mudas maiores que $18 \mathrm{~cm}$ não houve efeito significativo $(p>0,05)$ entre os regimes hídricos testados.

Maiores incrementos no diâmetro do coleto (Tabela 3) foram observados em mudas submetidas ao regime hídrico gradativo, independentemente do tamanho da muda. O regime hídrico controle proporcionou menor incremento em diâmetro do coleto em comparação aos demais regimes hídricos. Diferenças entre o tamanho da muda foram apenas detectadas no regime hídrico controle, em que as mudas menores que $18 \mathrm{~cm}$ apresentaram menor taxa de crescimento em diâmetro.

Em função do aumento no diâmetro do coleto e na redução da altura de mudas submetidas à restrição hídrica, houve redução da relação H/D (Tabela 3), com médias menores do que o regime hídrico controle independentemente do tamanho da muda. Contudo, mudas classificadas como menores do que $18 \mathrm{~cm}$ proporcionaram menores valores da relação $\mathrm{H} / \mathrm{D}$, exceto no regime hídrico controle.
Os diferentes regimes hídricos influenciaram no incremento de matéria seca radicular apenas em mudas menores do que $18 \mathrm{~cm}$ (Tabela 4), possibilitando, com a redução gradativa do regime hídrico, um aumento na matéria seca de raízes de até $90 \%$ em relação ao regime controle. Mudas maiores do que $18 \mathrm{~cm}$ apresentaram média de 13,2 mg por dia. Diferenças entre classes de altura foram observadas apenas quando da adoção do regime intercalar. Mudas maiores do que $18 \mathrm{~cm}$ apresentaram maior incremento da matéria seca radicular.

A taxa de incremento na matéria seca nos tecidos aéreos não foi influenciada pela altura da muda $(p>0,05)$. Os efeitos dos diferentes manejos hídricos proporcionaram maiores médias em comparação ao regime controle independentemente da altura da muda (Tabela 4). Em função da maior taxa de incremento da biomassa tanto em raízes quanto nos tecidos aéreos, a adoção do regime gradativo resultou em maiores médias para a taxa de crescimento absoluto, independentemente da altura da muda. 
TABELA 4: Incrementos na massa seca de raízes (MSR), nos tecidos aéreos (MSA) e taxa de crescimento absoluto (TCA) em função do tamanho e dos regimes hídricos em mudas de Maytenus ilicifolia na fase de rustificação.

\begin{tabular}{|c|c|c|c|c|c|c|}
\hline \multirow[b]{2}{*}{ Regime hídrico } & \multicolumn{2}{|c|}{ MSR } & \multicolumn{2}{|c|}{ MSA } & \multicolumn{2}{|c|}{ TCA } \\
\hline & G & $\mathbf{P}$ & G & $\mathbf{P}$ & G & $\mathbf{P}$ \\
\hline & \multicolumn{6}{|c|}{ - mg por dia --- } \\
\hline Controle & $10,8 \mathrm{aA}^{*}$ & 7,2 bA & $10,8 \mathrm{bA}$ & $11,6 \mathrm{bA}$ & $21,6 \mathrm{bA}$ & $18,8 \mathrm{bA}$ \\
\hline Intercalar & $13,6 \mathrm{aA}$ & $9,0 \mathrm{abB}$ & $25,5 \mathrm{aA}$ & $15,0 \mathrm{abA}$ & $39,1 \mathrm{aA}$ & $24,0 \mathrm{abB}$ \\
\hline Gradativa & $15,3 \mathrm{aA}$ & $13,7 \mathrm{aA}$ & $22,3 \mathrm{aA}$ & $21,6 \mathrm{aA}$ & $37,6 \mathrm{aA}$ & $35,3 \mathrm{aA}$ \\
\hline $\mathrm{CV}(\%)$ & \multicolumn{2}{|c|}{12,0} & \multicolumn{2}{|c|}{12,9} & \multicolumn{2}{|c|}{11,2} \\
\hline
\end{tabular}

* Médias seguidas da mesma letra minúscula nas colunas e maiúsculas nas linhas não diferem estatisticamente entre si ao nível de 5\% de probabilidade de erro pelo teste de Tukey. Em que: G: mudas com altura maior que $18 \mathrm{~cm}$; P: mudas com altura menor que $18 \mathrm{~cm}$.

Os efeitos dos diferentes manejos hídricos resultaram em menor extravasamento de eletrólitos do sistema radicular (Tabela 5) independentemente da altura da muda, enquanto mudas maiores do que $18 \mathrm{~cm}$ apresentaram menores valores de PER do que mudas menores do que $18 \mathrm{~cm}$ quando submetidas ao regime intercalar de irrigação.

No ato do transplantio não houve diferenças significativas $(p>0,05)$ para o teor relativo de água (TRA), que apresentou média de 80,5\%. Na avaliação da resistência ao déficit hídrico, a análise de variância relevou interação significativa entre regime hídrico e período de tempo sob estresse, e entre tamanho da muda e período de tempo sob estresse (Tabela 6).

Até a sexta semana, mudas mantidas sob irrigação em dias intercalados e redução gradativa dos dias de irrigação apresentaram maior TRA, indicando algum mecanismo de conservação de água em comparação ao regime hídrico controle (Tabela 6). Na nona semana, o maior valor de TRA foi obtido em mudas submetidas à redução gradativa da irrigação. O TRA manteve-se semelhante até a sexta semana, com redução após esse período independentemente do manejo hídrico e do tamanho da muda.

TABELA 5: Extravasamento de eletrólitos do tecido radicular em função do tamanho e dos regimes hídricos em mudas de Maytenus ilicifolia na fase de rustificação.

\begin{tabular}{llc}
\hline \multirow{2}{*}{ Regime hídrico } & \multicolumn{2}{c}{ Perda de eletrólitos de raízes (\%) } \\
\cline { 2 - 3 } & Grandes & Pequenas \\
\hline Controle & $47,3 \mathrm{aA}^{*}$ & $53,1 \mathrm{aA}$ \\
Intercalar & $31,9 \mathrm{bB}$ & $45,7 \mathrm{bA}$ \\
Gradativa & $38,4 \mathrm{bA}$ & $43,2 \mathrm{bA}$ \\
\hline CV $(\%)$ & & \\
\hline
\end{tabular}

* Médias seguidas da mesma letra minúscula nas colunas e maiúsculas nas linhas não diferem estatisticamente entre si ao nível de 5\% de probabilidade de erro pelo teste Tukey.

TABELA 6: Teor relativo de água nas folhas (\%) em função do tamanho e dos regimes hídricos em mudas de Maytenus ilicifolia na fase de rustificação.

\begin{tabular}{llll}
\hline & 3 semana & 6 semana & 9ª semana \\
\hline Regime hídrico x tempo & & & $65,6 \mathrm{bB}$ \\
\hline Controle & $71,9 \mathrm{bA}^{*}$ & $74,5 \mathrm{bA}$ & $67,5 \mathrm{bB}$ \\
Intercalar & $80,0 \mathrm{aA}$ & $79,6 \mathrm{aA}$ & $72,0 \mathrm{aB}$ \\
Gradativa & $81,5 \mathrm{aA}$ & $79,2 \mathrm{aA}$ & $70,3 \mathrm{aB}$ \\
\hline Tamanho x tempo & & & $61,4 \mathrm{bB}$ \\
\hline Grandes & $76,5 \mathrm{bA}$ & $77,3 \mathrm{aA}$ & \\
Pequenas & $79,1 \mathrm{aA}$ & $78,2 \mathrm{aA}$ & \\
\hline CV $(\%)$ & 3,6 & &
\end{tabular}

* Médias seguidas da mesma letra minúscula nas colunas e maiúsculas nas linhas não diferem estatisticamente entre si ao nível de $5 \%$ de probabilidade de erro pelo teste Tukey. Período em semanas refere-se ao período de tempo após o transplantio. 
Mudas menores do que $18 \mathrm{~cm}$, por possuírem em média $34 \%$ a menos de massa de matéria seca no sistema radicular (Tabela 4), teriam menor contato com o substrato e armazenariam maior quantidade de água no torrão, resultando em maior TRA nas folhas durante as primeiras três semanas sob restrição hídrica, além de possuírem uma área foliar cerca de $42 \%$ menor que as de maior tamanho, possibilitando menores perdas de água por transpiração. Com o tempo, por possuírem menor sistema radicular, as mudas não conseguiram explorar com maior eficiência a água disponível no substrato, fazendo com que o teor de água nas folhas fosse menor em comparação a mudas de maior tamanho (Tabela 6).

\section{Discussão}

A tolerância de uma planta ao déficit hídrico reflete as interações entre suprimento, demanda e regulação de água (HAASE, 2008). A redução da condutância estomática, das taxas de transpiração e, consequentemente, da assimilação de $\mathrm{CO}_{2}$ são respostas clássicas em plantas submetidas ao déficit hídrico (TAIZ; ZEIGER, 2009). Contudo, quando o déficit hídrico ocorre de maneira gradual, mudas de $M$. ilicifolia aclimataram-se à disponibilidade hídrica, mantendo mecanismos de assimilação de $\mathrm{CO}_{2}$ principalmente pelo aumento no consumo de $\mathrm{CO}_{2}$ intracelular, conforme observado na concentração interna de $\mathrm{CO}_{2}$ (Tabela 2).

Nas mudas expostas à irrigação intercalar, a concentração interna de $\mathrm{CO}_{2}$ foi menor que nos demais regimes hídricos, indicando que a menor concentração de $\mathrm{CO}_{2}$ difundido pelo mesófilo foliar é resultado da maior carboxilação como resposta compensatória a baixa taxa de assimilação, resultando em taxa de crescimento absoluto semelhante à de mudas submetidas à redução gradativa da irrigação.

O carbono assimilado em mudas maiores do que $18 \mathrm{~cm}$, submetidas à restrição hídrica, foi acumulado em maior proporção nos tecidos aéreos do que nos radiculares, pois incrementaram cerca de $121 \%$ a mais que no regime hídrico controle (Tabela 4). Já no sistema radicular, as taxas mesmo não significativas foram de 34\%. Em mudas menores do que $18 \mathrm{~cm}$, o acúmulo foi maior no sistema radicular tendo em vista que o incremento na parte aérea foi $58 \%$ maior do que no tratamento controle, e no sistema radicular esse incremento foi de $90 \%$.

O desenvolvimento do sistema radicular também está envolvido no processo de adaptação morfofisiológica em resposta ao estresse hídrico (BAÑON et al., 2006). O estresse aumenta a alocação de biomassa no sistema radicular, pois em condição de baixa disponibilidade de água no solo as plantas tendem a investir mais em crescimento radicular, permitindo explorar maior volume de solo e consequentemente aumentando a capacidade de absorção de água (GROSSNICKLE, 2005).

Pequenas diferenças de condutância estomática foram responsáveis por elevar a temperatura foliar, indicando que o aquecimento da folha é indicativo de redução na taxa de transpiração, limitando a perda de calor latente da radiação incidente no limbo foliar. Corroborando o exposto, Lima et al. (2014) reportaram um aumento de $1,4^{\circ} \mathrm{C}$ na temperatura foliar em mudas de Handroanthus impetiginosus (Mart. Ex DC.) submetidas a ciclos de restrição hídrica por quatro dias, durante quatro semanas.

O extravasamento de eletrólitos de células é uma reposta fisiológica característica em vegetais submetidos aos diferentes tipos de estresse (RÄISÄNEN et al., 2009; VILLAR-SALVADOR et al., 2013; VOLKWEIS et al., 2014). Esse fenômeno é amplamente usado como um indicativo do nível de dano ou da tolerância ao estresse, sendo que menores valores para o extravasamento de eletrólitos indicam a maior integridade das membranas biológicas.

Além disso, o teste é comparativo e específico para uma espécie, cujo vazamento de eletrólitos da raiz pode prever o desempenho global das mudas sob uma variedade de perturbações ambientais, externando sua qualidade (GROSSNICKLE, 2005). Por exemplo, o teste da perda de eletrólitos de raízes mostrou ser preditivo à sobrevivência de mudas de Enterolobium contortisiliquum [(Vell.) Morong] e Peltophorum dubium [(Spreng.) Taub] sob condições de déficit hídrico como reportado por Oro et al. (2016), que observaram uma forte correlação inversa entre o extravasamento de 
eletrólitos do sistema radicular e a sobrevivência das mudas sob restrição hídrica por até 45 dias.

A redução no extravasamento de eletrólitos foi inversamente relacionada ao ajustamento osmótico promovido pelo acúmulo de carboidratos não estruturais em raízes de mudas de Quercus ilex L. submetidas à rustificação por exposição a diferentes níveis de estresse hídrico, cujas mudas submetidas a um nível moderado de estresse ( $45 \%$ da capacidade de saturação do substrato) apresentaram um menor extravasamento de eletrólitos (VILLAR-SALVADOR et al., 2004), o que corrobora os resultados obtidos na presente pesquisa, tendo em vista que a redução da frequência de irrigação, seja gradativa ou intercalar, pode ter promovido um ajustamento osmótico, minimizando danos oxidativos nas membranas celulares do sistema radicular.

Quando o nível de estresse é moderado, a produção de formas reativas de oxigênio age como um mecanismo de defesa, ativando reações de síntese de osmolitos, oxidativas e regulatórias como na abertura e no fechamento de canais iônicos (DEMIDCHIK et al., 2014). Por exemplo, Kubis et al. (2014) observaram que o aumento na concentração de prolina no sistema radicular, induzido pela aplicação exógena de poliamina, foi responsável por reduzir o extravasamento de eletrólitos em raízes de Cucumis sativus cv. Dar, submetidas ao déficit hídrico. Portanto, mudas de M. ilicifolia com maior altura submetidas ao regime hídrico intercalar ou mudas submetidas à redução gradativa independentemente do tamanho possuem maior integridade das membranas celulares do sistema radicular, conforme Tabela 5 .

Em um curto período de tempo, a água disponível para a muda é aquela presente no substrato do recipiente. A longo prazo, a muda deve absorver umidade da solução do solo, dependente do crescimento e da exploração radicular (GROSSNICKLE, 2012). Mudas de menor altura, por possuírem menor área foliar, apesar de taxas transpiratórias semelhantes às das mudas de maior altura, consomem menos água e exploram um menor volume do solo ao longo do tempo, pois possuem em média $34 \%$ a menos de massa seca no sistema radicular (Tabela 4) e teriam menor contato com o substrato bem como armazenariam maior quantidade de água no torrão, resultando em maior TRA nas folhas durante as primeiras três semanas sob restrição hídrica, além de possuírem uma área foliar aproximadamente $42 \%$ menor que a das de maior tamanho, possibilitando menores perdas de água por transpiração. Com o tempo, por possuírem menor sistema radicular, essas mudas não conseguiram explorar com maior eficiência a água disponível no substrato, fazendo com que o teor de água nas folhas fosse menor em comparação ao das mudas de maior tamanho, o que justifica o menor teor de água nas folhas após nove semanas (Tabela 6).

Se o período de déficit hídrico a campo for relativamente curto, os efeitos benéficos da muda menor do que $18 \mathrm{~cm}$ poderiam ser suprimidos pela competição interespecífica característica em ambientes tropicais, tendo em vista que a competição com a vegetação adjacente por luz e por recursos do solo pode ser uma restrição importante para mudas de pequenas dimensões por possuírem uma reduzida taxa de crescimento inerente ao tamanho (WALSH et al., 2014). Se o período de deficiência hídrica for estendido, mudas com maiores dimensões poderão compensar as perdas por transpiração pela exploração de um maior volume de substrato pelas raízes (Tabela 6).

Corroborando o acima exposto, mudas altas $(30 \mathrm{~cm})$ de Pinus ponderosa (Lawson \& C. Lawson var. ponderosa $\mathrm{C}$. Lawson) resultaram em menor mortalidade a campo em condições de déficit hídrico e com competição com Triticum aestivum L. quando comparadas às mudas de menor altura $(20 \mathrm{~cm})$. Porém, quando não houve competição, não foram detectadas diferenças na sobrevivência em relação à altura das mudas, sendo consideradas de melhor qualidade as de maior tamanho (PINTO et al., 2012).

A perda da turgescência, decorrente da redução do teor de água nas folhas por transpiração reduz o potencial hídrico das plantas. Portanto, a manutenção da turgescência por condicionamento das mudas no viveiro durante alterações na disponibilidade de água para as plantas pode garantir sua sobrevivência, mediante a continuidade dos processos metabólicos.

Portanto, a rustificação por meio da redução gradativa do regime de regas aplicadas em mudas de 
Maytenus ilicifolia com maior tamanho $(>18 \mathrm{~cm}$ de altura) possibilita a obtenção de mudas com maior qualidade e rusticidade ao déficit hídrico. Já mudas de menor tamanho podem ser utilizadas se não houver fator limitante ao estabelecimento a campo.

\section{Agradecimentos}

À Fundação Araucária, à CAPES e ao CNPq pela concessão de bolsas aos autores.

\section{Referências}

BAÑON, S.; OCHOA, J.; FRANCO, J. A.; ALARCÓN, J. J.; SÁNCHEZ-BLANCO, M. J. Hardening of oleander seedlings by deficit irrigation and low air humidity. Environmental and Experimental Botany, Paris, v. 56, n. 1, p. 36-43, 2006.

BOEGER, M. R. T.; ESPÍNDOLA JR, A.; MACCARI JR, A.; REISSMANN, C. B.; ALVES, A. C. A.; RECKLI, F. L. Variação estrutural foliar de espécies medicinais em consórcio com ervamate, sob diferentes intensidades luminosas. Floresta, Curitiba, v. 39, n. 1, p. 215-225, 2009.

CLOSE, D. C. A review of ecophysiologically-based seedling specifications for temperate Australian eucalypt plantations. New Forests, Sydney, v. 43, n. 5-6, p. 739-753, 2012.

DEL CAMPO, A. D.; NAVARRO, R. M.; CEACERO, C. J. Seedling quality and field performance of commercial stocklots of containerized holm oak (Quercus ilex) in Mediterranean Spain: an approach for establishing a quality standard. New Forests, Sydney, v. 39, n. 1, p. 19-37, 2010.

DEMIDCHIK, V.; STRALTSOVA, D.; MEDVEDEV, S. S.; POZHVANOV, G. A.; SOKOLIK, A.; YURIN, V. Stress-induced electrolyte leakage: the role of $\mathrm{K}+$ - permeable channels and involvement in programmed cell death and metabolic adjustment. Journal of Experimental Botany, Oxford, v. 65, n. 5, p. 12591270, 2014.

DUARTE, M. R.; DEBUR, M. C. Stem and leaf morphoanatomy of Maytenus ilicifolia. Fitoterapia, Milan, v. 76, p. 41-49, 2005.

FIGUEIREDO, F. A. M. M. A.; CARNEIRO, J. G. A.; PENCHEL, R. M.; BARROSO, D. G.; DAHER, R. F. Efeito das variações biométricas de mudas clonais de eucalipto sobre o crescimento no campo. Revista Árvore, Viçosa, v. 35, n. 1, p. 1-11, 2011.

GROSSNICKLE, S. C. Why seedlings survive: influence of plant attributes. New Forests, Sydney, v. 43, n. 5-6, p. 711-738, 2012.

GROSSNICKLE, S. C. The importance of root growth in overcoming planting stress. New Forests, Sydney, v. 30, n. 2, p. 275-294, 2005.

HAASE, D. L. Understanding forest seedling quality: measurements and interpretation. Tree Planters Notes, Washington, v. 52, n. 2, p. 24-30, 2008.

JACOBS, D. F.; LANDIS, T. D. Hardening. In: DUMROESE, R. K.; LUNA, T.; LANDIS, T. D. (Ed.). Nursery manual for native plants: guide for tribal nurseries. Vol. 1. Washington: United States Department of Agriculture, Forest Service, 2009. p. 217-228.

KUBIS, J.; FLORYSZAK-WIECZOREK, J.; ARASIMOWICZJELONEK, M. Polyamines induce adaptive responses in water deficit stressed cucumber roots. Journal of Plant Research, Tokyo, v. 127, p. 151-158, 2014.

LIMA, P. R.; HORBACH, M. A.; DRANSKI, J. A. L.; ECCO, M.; MALAVASI, M. M.; MALAVASI, U. C. Avaliação morfofisiológica em mudas de Handroanthus impetiginosus (Mart. ex DC.) Mattos durante a rustificação. Floresta e Ambiente, Seropédica, v. 21, n. 3, p. 316-326, 2014.

NERY, J. T.; MARTINS, M. L. O. F.; BALDO, M. C. Correlação da precipitação do estado do Paraná com a anomalia da temperatura da superfície do mar do Pacífico Equatorial. Revista Brasileira de Agrometeorologia, Piracicaba, v. 10, n. 6, p. 305-316, 2002.

ORO, P.; DRANSKI, J. A. L.; MALAVASI, U. C.; MALAVASI, M. M. Frequência da irrigação ao final da produção em mudas de espécies lenhosas. Revista de Ciências Agroveterinárias, Lages, v. 15, n. 2, p. 94-102, 2016.

PELLICO NETTO, S.; BRENA, D. A. Inventário florestal. Curitiba: Editorado pelos autores, 1997. 316 p.

PINTO, J. R.; MARSHALL, J. D.; DUMROESE, R. K.; DAVIS, A. S.; COBOS, D. R. Photosynthetic response, carbon isotopic composition, survival, and growth of three stock types under water stress enhanced by vegetative competition. Canadian Journal of Forest Research, Ottawa, v. 42, n. 2, p. 333-344, 2012.

RÄISÄNEN, M.; REPO, T.; LEHTO, T. Cold acclimation of norway spruce roots and shoots after boron fertilization. Silva Fennica, Vantaa, v. 43, n. 2, p. 223-233, 2009.

RITCHIE, G. A.; LANDIS, T. D.; DUMROESE, K.; HAASE, D. L. Assessing plant quality. In: LANDIS, T. D.; DUMROESE, R. K.; HAASE, D. L. (Ed.). The container tree nursery manual: seedling processing, storage, and outplanting. Vol. 7. Washington: Department of Agriculture Forest Service, 2010. p. 17-82.

TAIZ, L.; ZEIGER, E. Fisiologia vegetal. 4 ed. Porto Alegre: Artmed, 2009. 848 p.

THOMAS, D. S. Survival and growth of drought hardened Eucaliptus pilularis $\mathrm{Sm}$. seedlings and vegetative cuttings. New Forests, Sydney, v. 38, p. 245-259, 2009.

VALE, F. X. R.; FERNANDES FILHO, E. I.; LIBERATO, J. R.; ZAMBOLIM, L. Quant: A software to quantify plant disease severity. In: International Workshop on Plant Disease Epidemiology, 2001, Ouro Preto. Proceedings... Ouro Preto: The International Society of Plant Pathology, 2008. Vol. 8. p. 160.

VILLAR-SALVADOR, P.; PEÑUELAS, J. L; JACOBS, D. F. Nitrogen nutrition and drought hardening exert opposite effects on the stress tolerance of Pinus pinea L. seedlings. Tree Physiology, Victoria, v. 33, p. 1-12, 2013

VILLAR-SALVADOR， P.; PLANELLES， R.; OLIET, J.; PEÑUELAS-RUBIRA, J. L.; JACOBS, D. F.; GONZÁLEZ, M. Drought tolerance and transplanting performance of holm oak (Quercus ilex) seedlings after drought hardening in the nursery. Tree Physiology, Victoria, v. 24, p. 1147-1155, 2004.

VOLKWEIS, C. R.; DRANSKI, J. A. L.; ORO, P.; MALAVASI, U. C.; MALAVASI, M. M. Efeito da tigmomorfogênese na morfometria de mudas de Maytenus ilicifolia (Schrad.) Planch. Ciência Florestal, Santa Maria, v. 24, n. 2, p. 339-342, 2014. 
WALSH, D.; ROSSI, S.; LORD, D. Size and age: intrinsic confounding factors affecting the responses to a water deficit in black spruce seedlings. Journal of Biogeosciences and Forestry, Rome, v. 7, p. 1-09, 2014. Tree Physiology, Victoria, v. 24, p. 1147-1155, 2004.
WILNER, J. Results of laboratory tests for winter hardiness of woody plants by electrolyte methods. Proceedings of the American Horticultural Society, Ann Arbor, v. 66, p. 93-99, 1955. 